\title{
Research on Financing of Small and Medium Sized Enterprises in China Based on P2P Net Loan Platform
}

\author{
Zhu Lihao \\ Hangzhou College of Commerce, Zhejiang Gongshang University, Hangzhou, China
}

\section{Email address:}

diaobo64093@163.com

\section{To cite this article:}

Zhu Lihao. Research on Financing of Small and Medium Sized Enterprises in China Based on P2P Net Loan Platform. Science Innovation. Vol. 5, No. 6, 2017, pp. 386-391. doi: 10.11648/j.si.20170506.20

Received: November 3, 2017; Accepted: November 10, 2017; Published: December 6, 2017

\begin{abstract}
Small and medium-sized enterprises as an important part of China's economic development environment, already accounted for more than $99 \%$ of the proportion of Chinese enterprises accounted for. It not only made innovations in China's social production, promoted the economic prosperity, but also eased the pressure of urban employment on the basis of increasing exports. However, small and medium-sized enterprises still show weak trend in the development of market financing. On the one hand, the small and medium-sized enterprises are facing the pressure from the aspects of production, such as the RMB appreciation, rising labor costs, increase the cost of raw materials and financing costs increase, are factors that restrict loans through traditional banks and other financial institutions to small and medium sized enterprises; on the other hand, under the new situation of investment information the two sides of the small and medium-sized enterprise financing, the asymmetry of financial and non-financial information, lack of transparency and credit assessment difficult, are also important reasons restricting SMEs to bank loans. Moreover, small and medium-sized enterprises in the loan or in the process of financing, although the loan amount is small, but the loan frequency is high, and the financing period is relatively short, and the traditional financial institutions investment funds longer approval time has obvious difference, leading to small and medium-sized enterprises is difficult to adapt to the mode of financing and loan. But with the entry Internet plus era, the rapid development of computer technology, network technology, information and communication technology, making all kinds of Internet related technology, is gradually integrated into the financial sector, while the P2P (Peer to Peer point) net loan mode, is an important breakthrough of the traditional network technology into the financial sector. This not only makes the traditional lending mode change, but also makes the modern financial industry division of labor and specialization, is gradually replaced by the Internet and related technologies. It makes the meaning of it more obvious. Based on this, this paper uses the literature research and game analysis, the problems of the SME financing P2P net loan platform based on making research, and summarizes the measures should be taken: P2P net loan platform, small and medium-sized enterprises, investors, regulators, and credit evaluation institutions, jointly solve the financing difficulties of small and medium-sized enterprises Chinese the problem.
\end{abstract}

Keywords: P2P Net Loan Platform, Small and Medium-Sized Enterprises, Financing Difficulties, Financial System

\section{基于P2P网贷平台的中国中小企业融资研究}

\author{
朱立豪 \\ 杭州商学院, 浙江工商大学, 杭州, 中国 \\ 邮箱 \\ diaobo64093@163.com
}

摘要：中小企业作为中国经济发展环境中的重要组成部分, 已然在中国企业占比中超过 $99 \%$ 的占比率。其不仅对中国 社会生产进行了创新, 对经济繁荣做出了促进, 更在增加出口额的基础上, 有效缓解了城镇就业压力。但中小企业在 
进行市场融资发展中, 仍显示出疲软的态势。一方面, 中小企业面临着来自于生产方面的压力, 如人民币的升值、劳 动力成本的提高、原材料成本的增加、以及资金融通成本的加大等, 都是制约中小企业通过传统银行等金融机构进行 贷款的因素；另一方面，新形势下投融资双方的信息不对称、中小企业财务信息与非财务信息缺乏透明化、以及信用 评估困难等问题，也都是限制中小企业进行银行贷款的重要原因。并且，中小企业在进行贷款或融资过程中，虽然贷 款数额偏小，但贷款频率较高，且融资周期相对较短，这与传统金融机构所投入的较长资金审批时间具有明显的差异 性，从而导致中小企业很难适应此种融资或贷款模式。但随着互联网+时代的进入，计算机技术、网络技术、以及信 息通信技术的飞速发展, 使得各类与互联网相关的技术形式, 正逐步融入到金融领域, 而P2P (Peer to Peer点对点) 网 贷模式, 便是网络技术融入传统金融领域的重要突破。这不仅促使传统借贷模式发生了模式上的转变, 更使得现代金 融业的分工与专业化, 正在逐步被互联网及相关技术所替代。由此使得其所展现出的意义更加明显。基于此, 本文采 用文献研究、博亦分析等方式, 对基于P2P网贷平台的中小企业融资问题做出了研究, 并总结出: 应从P2P网贷平台、 投资者、中小企业、监管机构、以及信用评估机构等方面采取措施，共同解决中国中小企业融资难的问题。

关键词： $\mathrm{P} 2 \mathrm{P}$ 网贷平台, 中小企业, 融资困境, 金融体系

\section{1. 引言}

新时代背景下的融资难问题, 一直是困扰中小企业发 展的制约因素。一方面，传统金融机构在审批流程、借贷 时间、以及人工成本投入等方面, 都存在着诸多的问题, 这使得对于贷款少、效率快、且借贷周期较为频繁的中小 企业而言, 更是无法有效解决自身的融资问题。对此, 随 着网络技术的发展, 以及其与金融行业的融合, 使得 P $2 \mathrm{P}$ 网络贷款平台得以出现, 并逐渐成为解决中小企业融资难 的有效措施，更使之成为金融行业中的有益融资方式补充。 根据第一网贷（深圳市钱诚互联网金融研究院）所发布的 《2017年上半年全国P2P网贷行业报告》[1]显示，通过近 10 年的成长与发展, 截至2017年6月底, 中国P2P网络借贷 机构总数为 2359 家, 虽然较之 2016 年同比降 $11.12 \%$, 但较 之2017年5月则环比提升 $2.25 \%$ 。而贷款余额更是达到了 1.45 万亿, 同比增强近 $72 \%$, 环比增长近 $20 \%$ 。通过此种 数据可以清晰的看出, 随着现阶段网络技术的发展, 各类 云计算以及移动支付功能的实现，使得基于信息网络技术 背景的P2P网贷平台, 已经日益壮大。然而, 张建江[2]在《P2P 网贷背景下的中小企业融资新途径分析》中指出: “虽然P2P网 络借贷能够解决魏国中小企业的融资困境, 但此种网络化, 且趋向于“民间借贷”的融资模式, 也随着其成长与发展, 而促使更多的问题与不足得以显露”。并且，雷倩华[3]也在 《中小企业互联网融资中的信息不对称、融资约束与第三方鉴 证》中阐述出: “P2P网络借贷行业的准入门槛相对较低、 借贷双方的信息不对称、行业监管难度较高、以及与之相 关的法律法规等缺乏完善性等。此类风险的生成与留存, 必然会造成借贷双方利益上的损失, 并会严重影响到中小 企业的融资行为。”在此基础上, 卢馨 [4]通过《P2P网络借 贷的运行模式与风险管控》一文中提出：“网络贷款平台 在降低小微企业融资成本方面具有较大的优势, 并为众多 中小企业开辟出了全新的融资渠道, 但由 $\mathrm{P} 2 \mathrm{P}$ 网贷所引起 的消极因素问题，也是困扰金融行业可持续发展的典型问 题。”这不仅表明P2P网贷平台的构建, 能够有效缓解和解 决中小企业融资困难的问题, 但更要对P2P网贷平台、中 小企业、投资者等方面进行细致的分析与研究。唯有如此, 才能确保中小企业利用P2P网贷平台所产生的融资问题得
以消除, 也才能确保中小企业融资困难问题得到根本性的 解决。

\section{P2P网贷平台概述}

\section{1. P2P网贷的定义及构成主体}

P2P来源于计算机技术应用，原意为Peer to Peer（对 等网络或点对点网络）。P2P网络中所涵盖的信息内容与 服务等, 都在各个节点中分布, 这也使得服务器与汶览器 在部分功能性上趋于等同。而金融行业将P2P的网络概念 做了引用, 从而生成针对金融行业的 $\mathrm{P} 2 \mathrm{P}$ 金融或P2P信贷, 且统一归属于互联网金融体系之中。

P2P网贷（P2P金融），即是处于差异性网络节点间的 小额借贷交易, 需要通过电子商务化的网络平台, 来进行 借贷双方的借贷关系确立, 并通过此种网络平台, 进行借 贷相关手续的办理 [5]。在此过程中, 无论是借款者或是贷 款者, 都可在网络化的 $\mathrm{P} 2 \mathrm{P}$ 网贷平台中, 进行自身需求的 发布。如投资者所发布的借款信息、额度、利息、还款方 式、以及还款时间等等; 而借款人则可将自身的贷款需求 在平台上进行发布, 以此便于借款者更为清晰、明确的找 寻到所需融资的企业。进而促进借贷双方的合作目的达成 [6]。由此可见, P2P网贷平台共由三方面组成, 分别为投 资人、借款人、以及进行交易的网络借贷平台。而所涉及 到的融资流程, 也可通过下图1进行表示。

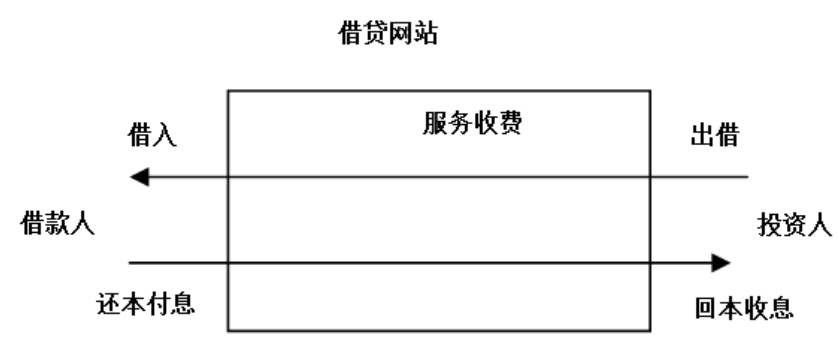

图1 P2P网络借贷平台融资流程图。 


\section{2. P2P网贷平台的发展现状}

\subsection{1. 平台规模及数量成倍增长，问题也逐步呈现}

P2P网贷模式的出现是在2005年的英国，而中国首家 成立的P2P网贷平台, 则是2007年在上海成立的拍拍贷。 在P2P网贷模式发展初期的几年内, 中国有且仅有P2P网贷 平台近10家，直到2011年起，中国金融行业迎来了网络化 的发展空间, 这使得P2P网贷平台由前期的近10家，直接 增长至50家[7]。而到2013年末, 中国P2P网贷平台已经增 至800家。截至2017年6月, 虽然中国现有P2P网贷机构出 现了小幅的回落, 但仍达到2300余家 [8]。然而, P2P网贷 平台的兴起与发展, 其道路并非一帆风顺, 而是在经历过 跑路事件、行业洗牌、资本遇冷、以及政策规范等趋势影 响下, 逐渐趋于平稳且缓慢的增长势头。

\subsection{2. 平台借款期限短, 利率水平趋于理性}

依照网贷行业所提供出的行业资讯，在现阶段的网贷 行业中，通过P2P网贷模式进行借贷款，且期限 $\leq 30 \mathrm{~d}$ 的网 贷平台约战行业比例的 $6 \%$ 左右，处于 $30 \mathrm{~d} \leq$ 期限 $\leq 90 \mathrm{~d}$ 的网 贷平台占比 $34 \%$, 而借款期限在 $90 \mathrm{~d} \sim 180 \mathrm{~d}$ 之内的更是高达 $42 \%, 180 \mathrm{~d} \sim 360 \mathrm{~d}$ 的则占比 $15 \%$, 借款期限超出 1 年的网络 贷款, 仅占比 $3 \%$ [9]。由下图2所示。由此说明, 进行P2P 网络贷款的中小企业, 所平均借款期限的高峰期, 处于 1 个月 半年之间。这与传统金融机构所开展的借贷业务相 比，无疑是具有较短借款期限的。

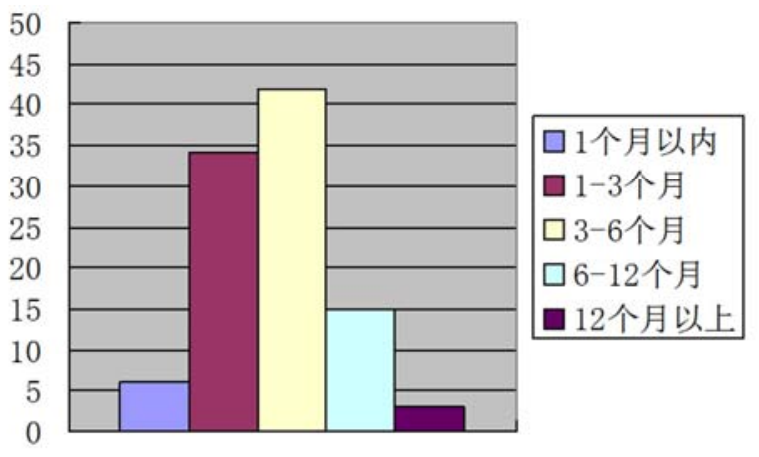

借贷期限占比率 $(\%)$

图2 各个平均期限区间平台分布图。

依照多方数据平台所提供的收益信息分析, 网贷行业 平均收益率在 $15 \%-20 \%$ 之间，而超出 $25 \%$ 的业内机构， 仅占 $7.03 \%$ 。同时, 高利率网贷平台的占比率相对较低, 这也是中国网贷行业趋于理性发展的实际体现形式 [10]。 此外, 网贷平台的综合收益率也呈现出逐步下滑的趋势, 这更加清晰的表明, 中国网贷行业正逐步进入到稳步发展 的区间之内。

\section{3．基于P2P网贷平台的中小企业融资博弯分析}

\section{1. 博弃论要素}

所谓的博弯论研究, 即是人们在互动环境中所做出的 策略性选择的学科研究。随着博弯理论在社会生产与经济
发展中的应用逐渐增多, 促使其成为影响到经济决策的重 要内容 [11]。利用博弯论对P 2 P网贷平台、中小企业、以 及投资者之间的分析，能够促使各方在掌握其他两方策略 的基础上, 为自身谋求最大利益。通常情况下, 博弯论中 所涵盖的要素如下图3所示。

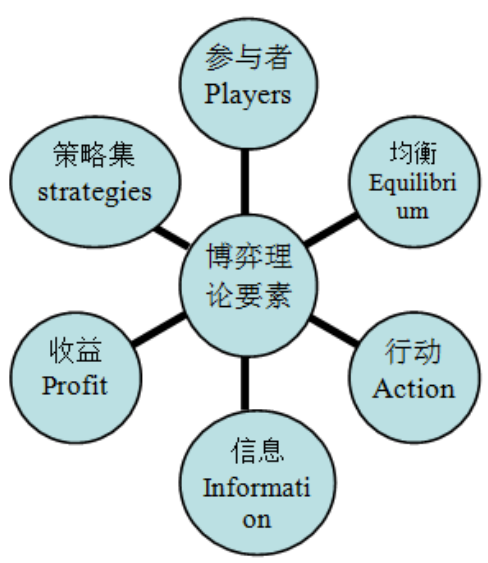

图3 博亦理论要素构成图。

（1）参与者（players）：在进行博弯活动中，凡能 够进行自主决策的主体, 即为参与者, 其是一类人或一个 整体的代名词。而针对参与者之间的关系，又可将此类博 弯划分为“双方博弯”或“多方博弯”[12]。文中所涉及到的 参与者为 $\mathrm{P} 2 \mathrm{P}$ 网贷平台、中小企业、以及投资者，且三者 间关系紧密，这使得三者间所构成的关系类型即为“多方 博弯”。

（2）策略集（strategies）：所谓策略，即是贯穿于 活动之中的战略方案，而策略集，则是将众多参与者的个 人策略进行整合而形成的集合部分，便是策略集。若策略 集中战略组合为有限的, 则此类博弯便是有限博弯, 反之, 则称之为无限博弯 $[13][14]$ 。而在进行网络化借贷活动中, 若以中小企业决策优先, $\mathrm{P} 2 \mathrm{P}$ 网贷平台与投资者决策延后, 则会生成如下决策内容:（还款、放款）、（不还款、放 款）, 或（还款、不放款）、（不还款、不放款）,同时, P2P网贷平台与投资者, 也会由此做出与之相对应的决策。

（3）收益（profit）：这里所说的收益, 即是在博弯 结束后, 所产生出的博弯内收益。而收益的多少, 既体现 在参与主体的决策方面, 又体现出其他参与者的决策情况。 文中所产生收益的博弯者为三类, 即P $2 \mathrm{P}$ 网贷平台、中小 企业、以及投资者。

（4）信息（information）：在博弯活动中, 参与者分 别对其他参与者的基本特性与行动标准进行掌握, 便是对 信息的获取与掌握 [15]。在网络借贷环节中, P2P网贷平 台、中小企业、以及投资者三方, 均分别知道其他两方的 基本特性与行动标准等信息内容。

（5）行动（action）：参与者所产生出的决策变量, 即可称为行动。若将参与者的行动以离散型函数表示, 则 各个决策者有且仅有两种行动。针对网贷活动, 便可归纳 为: 投资者有放款与不放款两种行动; 中小企业有还款与 不还款两种行动; 而 $\mathrm{P} 2 \mathrm{P}$ 网贷平台则有追究与不追究两种 行动。而针对中小企业可能会出现的不还款现象, P2P网 贷平台应在采用严格的审核流程基础上，同步进行相关激 
励措施的制定与实施, 以此促进中小企业在借款后, 能够 在规定的时间内进行还款行动, 从而在减少投资者损失的 同时，也能促使 $\mathrm{P} 2 \mathrm{P}$ 网贷平台受到经济与名誉等方面的损 害[16]。

（6）均衡 (equilibrium)：此处所说的均衡, 也可称 之为非合作模式的博弯均衡状态。其主要思想体现在：无 论其他博弯对手做出如何的决策行动, 参与主体所做出的 决策恒定, 即通常所说的支配性策略。在网络借贷活动中, 无论是中小企业, 或是投资者和 $\mathrm{P} 2 \mathrm{P}$ 网贷平台, 都认为自 身已经做出针对其他任意两方最为有利的决策内容, 则此 时所形成的策略集, 就称之为博弯的纳什均衡 [17]。这不 仅是博弯活动所积极寻求的均衡点, 更是促进各方利益最 大化的有效阶段。

\section{2. P2P网贷平台、中小企业、投资者间的博弯分析}

博弯分类中涵盖完全信息博弯和不完全信息博弯, 且 由采取策略集行动的先后顺序, 又可划分成静态博弯与动 态博峦两类。具体如表1所示。针对时下现状, 由于 P2P 网贷平台、中小企业、以及投资者三方面, 分别对其他博 峦参与者的信息、策略、以及行动等不能做到全面性的了 解和掌握, 即通常所说的信息不对称情况, 这使得在多方 博弯模式下, 便要应用到不完全信息博弯。而静态博弯与 动态博弯均为参与者在博峦活动中可能会出现的行为内 容, 则应分别做出分析。

表1 博弯分析分类表。

\begin{tabular}{lll}
\hline 类别 & 静态博栾 & 动态博弯 \\
\hline 完全信息条件 & 完全信息静态博栾 & 完全信息动态博栾 \\
不完全信息条件 & 不完全信息静态博弯 & 不完全信息动态博弯 \\
\hline
\end{tabular}

博弯分析中所涉及到的信息变量如下:

$\mathrm{M}_{1}$ ：网贷平台投资者的投资金额

$\mathrm{i}_{1}$ ：投资金额的银行利率

$\mathrm{i}_{2}$ ：中小企业在P $2 \mathrm{P}$ 网贷平台借款的利息 $\left(\mathrm{i}_{2}>\mathrm{i}_{1}\right)$

$\mathrm{M}_{2}$ ：中小企业借款投资项目的收益

Z: P2P网贷平台追究中小企业违约时需付成本

q：中小企业被认定“信用低”概率

q：中小企业被认定“信用高”概率

$\mathrm{v}$ ：中小企业违约后自身信用所受影响的系数

实际生活中, 在信息不完全态势下, 博弯参与者的各 方, 均会进行自身策略与行动的调整, 而其他参与者仅能 够了解到部分信息内容, 如此便无法精确掌握另外两方参 与者所做出的策略与行动。这使得不完全信息的静/动态 博弯成为了必然。对此, 进行不完全信息的静/动态博弯 分析。依据所设定的参数关系, 中小企业存在低信用的概 率是 $\mathrm{q}$, 而高信用概率为 $1-\mathrm{q}$, 由此便可推出 $\mathrm{P} 2 \mathrm{P}$ 网贷平台 的投资者, 会因 $\mathrm{q}$ 的出现, 而拒绝为中小企业放款, 而当 1-q时, 便可进行放款行动。一方面, P2P网贷平台, 会依 照中小企业所产生出的众多历史交易记录, 来为其建立起 具有信用等级的参与者档案; 另一方面, P2P网贷平台还 要对进行借款的中小企业做出信用奖励及相应的借贷扣 除, 尤其对于信用较低, 但却能按时还款的中小企业, 更 要进行激励政策的实施与促进。若依照信用等级对借款额 度做出适应性调整, 且进行借款利率上的优惠, 则中小企 业在履行约定还款, 或违约不还款使, 所产生出的影响系 数将会发生明显变化 [18]。是以, 若中小企业来履行约定, 并完成还款动作, 则其信用度为 $\mathrm{M}_{1} * \mathrm{v}$, 反之, 将在 $\mathrm{P} 2 \mathrm{P}$ 网 贷平台中扣除 $\mathrm{M}_{1}{ }^{*} \mathrm{v}$ 的信用度。如下表2、表3所示。

表 2 低信用中小企业及投资者的博弯矩阵表。

\begin{tabular}{lll}
\hline 博亦参与者 & 低信用、履约 & 低信用、违约 \\
\hline 投资者: 放款 & $\mathrm{M}_{1}\left(\mathrm{i}_{2}-\mathrm{i}_{1}\right) ; \mathrm{M}_{2}-\mathrm{M}_{1} * \mathrm{i}_{2}+\mathrm{M}_{1}{ }^{*} \mathrm{v}$ & $-\mathrm{M}_{1}\left(1+\mathrm{i}_{1}\right) ;, \mathrm{M}_{1}+\mathrm{M}_{2}-\mathrm{M}_{1}{ }^{*} \mathrm{v}$ \\
投资者: 不放款 & $\mathrm{M}_{1} *_{1_{1}} ; \mathrm{M}_{1}{ }^{*} \mathrm{v}$ & $\mathrm{M}_{1} * \mathrm{i}_{1} ;-\mathrm{M}_{1}{ }^{*} \mathrm{v}$ \\
\hline
\end{tabular}

表3 高信用中小企业及投资者的博栾矩阵表。

\begin{tabular}{lll}
\hline 博亦参与者 & 高信用、履约 & 高信用、违约 \\
\hline 投资者: 放款 & $\mathrm{M}_{1}\left(\mathrm{i}_{2}-\mathrm{i}_{1}\right) ; \mathrm{M}_{2}-\mathrm{M}_{1}{ }^{*} \mathrm{i}_{2}+\mathrm{M}_{1}{ }^{*} \mathrm{v}$ & $-\mathrm{M}_{1}\left(1+\mathrm{i}_{1}\right) ;, \mathrm{M}_{1}+\mathrm{M}_{2}-\mathrm{M}_{1}{ }^{*} \mathrm{v}$ \\
投资者: 不放款 & $\mathrm{M}_{1} *_{\mathrm{i}_{1}} ; \mathrm{M}_{1}{ }^{*} \mathrm{v}$ & $\mathrm{M}_{1}{ }^{*} \mathrm{i}_{1} ;-\mathrm{M}_{1}{ }^{*} \mathrm{v}$ \\
\hline
\end{tabular}

首先, 依照P2P网贷平台投资者方面做出分析:

在 $\mathrm{q}$ 出现, 且中小企业违约, 但1-q同步, 且中小企业 履约时, 投资者所进行的放款或不放款选择, 所产生的期 望收益分别为:

$$
\begin{gathered}
-\mathrm{M}_{1}\left(1+\mathrm{i}_{1}\right) * \mathrm{q}+\mathrm{M}_{1}\left(\mathrm{i}_{2}-\mathrm{i}_{1}\right) *(1-\mathrm{q}) \\
\mathrm{M}_{1} * \mathrm{i}_{1} * \mathrm{q}+\mathrm{M}_{1} * \mathrm{i}_{1} *(1-\mathrm{q})
\end{gathered}
$$

若 $\mathrm{q}<\left(\mathrm{i}_{2}-2 \mathrm{i}_{1}\right) /\left(1+\mathrm{i}_{2}\right)$ 时，投资者放款

若 $q \geq\left(i_{2}-2 i_{1}\right) /\left(1+i_{2}\right)$ 时，投资者不放款

其次，依照中小企业方面做出分析:

若P2P网贷平台中的投资者, 在进行放款与不放款的 选择中, 对高信用的中小企业进行放款, 而对低信用的中
小企业采取不放款策略, 则对于中小企业所采取的履约和 违约策略而言, 其希望能够得到的收益分别为:

$$
\begin{gathered}
\mathrm{M}_{1} * \mathrm{v} * \mathrm{q}+\left(\mathrm{M}_{2}-\mathrm{M}_{1} * \mathrm{i}_{2}+\mathrm{M}_{1} * \mathrm{v}\right) *(1-\mathrm{q}) \\
\left(-\mathrm{M}_{1} * \mathrm{v}\right) * \mathrm{q}+\left(\mathrm{M}_{1}+\mathrm{M}_{2}-\mathrm{M}_{1} * \mathrm{v}\right) *(1-\mathrm{q})
\end{gathered}
$$

若 $\mathrm{q}<\left(\mathrm{i}_{2}-2 \mathrm{i}_{1}\right) /\left(1+\mathrm{i}_{2}\right)$ 时, 中小企业还款 若 $q \geq\left(i_{2}-2 i_{1}\right) /\left(1+i_{2}\right)$ 时, 中小企业不还款 最后, 汇总分析:

在经过不等式的解析后能够得出结论, 即在当 $(1-2 \mathrm{v}+\mathrm{i} 2) /(1+\mathrm{i} 2)<\mathrm{q}<\left(\mathrm{i}_{2}-2 \mathrm{i}_{1}\right) /\left(1+\mathrm{i}_{2}\right)$ 时，投资者 会再网贷平台中进行资金的投入，而中小企业也会做出还 款选择。所得到的不等式范围, 会因 $\mathrm{v}$ 变大而随之增大, 即中小企业履约时, P2P网贷平台会对其进行相应的信誉 
度奖励, 这使得中小企业获取到贷款的机率也在逐渐提升, 促使不等式范围得以扩大。而通过对不等式的化简来看, 1- $\left(2 \mathrm{v} /\left(1+\mathrm{i}_{2}\right)\right)<\mathrm{q}<1-\left(\left(2 \mathrm{i}_{1}+1\right) /\left(1+\mathrm{i}_{2}\right)\right) ，$ 表明 $\mathrm{q}$ 与 $i_{2}$ 存在正相关关系, 而和 $i_{1}$ 则存在负相关关系。当P $2 P$ 网 贷平台所生成的贷款利率 $\mathrm{i}_{2}$ 增大，则中小企业发生违约的 机率便随之增大, 反之则违约机率变小。同时, 若银行存 款利率 $i_{1}$ 逐渐增大，则投资者会将资金大量的投入到银行
等传统机构中, 以降低投入风险。此时, 中小企业通过P $2 \mathrm{P}$ 网贷平台所获取到有效贷款的机率也将随之减小。对此, 中小企业也应进一步提升自身的信用标准与等级, 以此来 增进贷款机率 [19]。而中小企业为提升自身信用程度, 将 导致违约现象发生降低。

由此所生成的不完全信息的静态博亦分析，也可做出 不完全信息的动态博弯分析内容。具体以下图4所示。

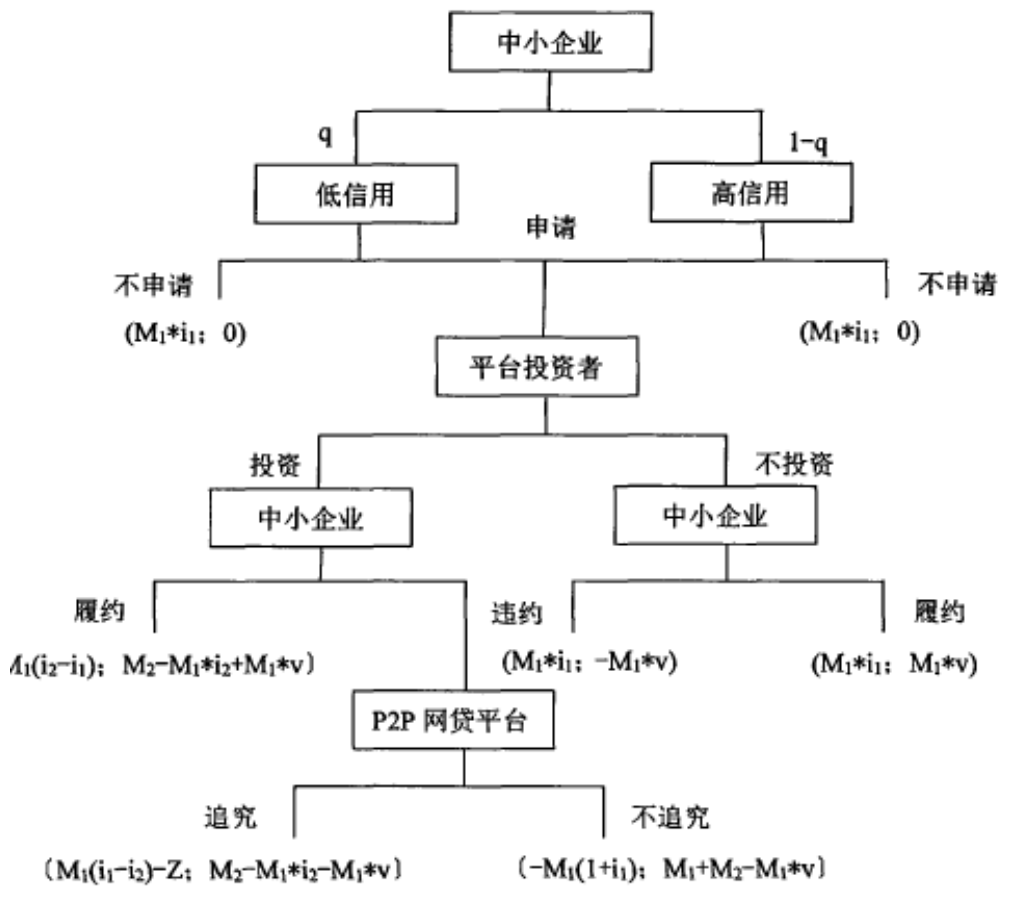

图4 不完全信息的动态博亦流程图。

依照不完全信息的动态博亦流程, 以及上文提到的不 完全静态博亦算法, 能够得出以下分析结果:

首先，投资者角度分析：

若 $q<\left(i_{2}-2 i_{1}\right) /\left(1+i_{2}\right) ，$ 则投资者进行放款

若 $q \geq\left(i_{2}-2 i_{1}\right) /\left(1+i_{2}\right) ，$ 则投资者放弃投资；

其次，中小企业决策分析：

若 $\mathrm{q}>\left(1-2 \mathrm{v}+\mathrm{i}_{2}\right) /\left(1+\mathrm{i}_{2}\right)$ 中小企业履约还款

若 $q \leq\left(1-2 v+i_{2}\right) /\left(1+i_{2}\right)$ 则中小企业违约不还款

最后, 汇总分析:

若P2P网贷平台所建立起来的信用激励机制缺乏完善 性时, 则 $\mathrm{v}$ 值会随之变小, 且若 $\mathrm{v}$ 值趋于 0 时, 中小企业的 行动将无限接近于 1 。并且, 由上述不等式的解析可知, $q$ 与 $\mathrm{i}_{2}$ 的关系为正相关, 而与 $\mathrm{i}_{1}$ 则为负相关关系。由此可明确 判断出: 现阶段的P2P网贷平台在运营过程中, 会受到信 息不对称因素的影响，从而导致中小企业的融资问题无法 得到本质上的解决。对此, 应采取其他辅助措施来应对中 小企业融资问题。

\section{4. 中小企业的融资启示}

现阶段, 中小企业在通过P2P网贷模式进行贷款的获取 过程中, 仍然有诸多劣势与弊端的存在。如P2P网贷平台的 身份模糊和监管缺失, 使得很多网贷的准入门槛过低, 这
使得中小企业在进行贷款时所生成的风险无形中增大。同 时, 很多缺乏规范性的 $\mathrm{P} 2 \mathrm{P}$ 网贷平台在进行业务办理时, 不 仅不具备良好的业务水平，更使得贷款利率留存在较高的 标准之下。一旦出现借贷问题，则投资者的利益也将受到 极大的损害[20]。针对此种情况，中小企业应从以下几方面 做好自身工作内容，以此确保融资困境得到良好解决。

首先，中小企业应建立并健全企业自身的财务体系， 在进行正常生产与运营的过程中, 将资金更为合理的分配, 以此减少出现坏账或死账的情况, 确保企业资金链维持稳 定。

其次，在进行对外交流与合作的过程中，应极力注重 自身的信用与信誉, 良好信用的建立, 不仅能够为中小企 业进行更好的品牌营销, 更能在进行融资及信贷抵押过程 中, 以良好的企业形象迎来更为宽广的发展机遇。同时, 在进行P2P网贷时，更要在考量网贷平台与投资者相关信 息的同时，确保所贷款的金额符合企业发展的需求，并使 之与企业的实际经济情况相匹配, 避免因目标的盲目设定, 而造成后续缺乏良好的资金偿还能力, 进而发生违约现象 [21]。

最后，更为清晰、准确的掌握中小企业自身的实际情 况, 如组织架构、资本结构、盈利模式、运维标准等。中 小企业所披露出的信息越多，出现信息不对称的情况也将 由此减少或降低，投资者与P2P网贷平台也将对企业产生 
出更高的信任度[22]。一方面, 便于投资者将资金通过P2P 网贷平台借贷给企业, 另一方面, 也便于P2P网贷平台积 极实施针对中小企业的奖励机制, 从而促使中小企业融资 问题，能够形成良性的循环，而此类融资难问题也将得到 本质上的解决。

\section{5. 结论}

新形势下，P2P网贷平台对中国中小企业融资问题的 解决, 发挥出了积极的作用。但由于P2P网贷平台、投资 者、以及中小企业间的博弯关系，使得中小企业在特定的 环境或融资约束条件下，会发生违约或不还款等问题，这 不仅会造成P $2 \mathrm{P}$ 网贷平台与投资者的利益损失，更会导致 中小企业的信用度降低, 从而在未来的运营过程中, 会受 到极大的市场制约。基于此，应对 P2P网贷平台、投资者、 以及中小企业三者间的博弯关系做出明确的差异性划分, 并总结出当处于何种条件时, 将会导致纳什均衡情况的出 现，这也将会促使中小企业的融资问题得到解决，并促使 三方的利益达到最大化。此种方式不仅是解决中小企业融 资困难的根本性方法, 更是促使其他行业及领域良性发展 的重要举措与路径。

\section{参考文献}

[1] 陈晓俊. P2P网贷行业十周年发展报告 [J]. 金融博览, 2017(14):26-29。

[2] 张建江. P2P网贷背景下的中小企业融资新途径分析[J]. 商 业经济，2015,(10):99-100。

[3] 雷倩华. 中小企业互联网融资中的信息不对称、融资约束与 第三方鉴证 $[J]$. 上海金融学院学报, 2015,(06):28-36。

[4] 卢馨, 李慧敏. P2P网络借贷的运行模式与风险管控[J]. 改 革, 2015(2):60-68。

[5] 林辉, 杨昒. 互联网金融及其在中小企业融资中的应用研究 [J]. 华东经济管理，2016,30(02):8-13+185。
[6] 李慧敏, 王淑梅, 董梦瑶. 中小企业P2P融资的SWOT分析 [J]. 财会通讯，2016,(08):19-20。

[7] 张舒婷, 詹人权, 刘倩. 浅谈中小企业利用 $\mathrm{P} 2 \mathrm{P}$ 网贷融资的 现状 [J]. 现代经济信息, 2016,(05):303+305。

[8] 谢明辰. 新常态下中小企业融资渠道的创新研究[J]. 宿州学 院学报, 2016,31(04):22-26+50。

[9] 周嗣超. 从p2p网贷浅析中小企业融资新途径[J]. 财经界(学 术版), 2015,(11):132。

[10] 薛海燕, 隋静. 互联网金融时代中小企业P2P融资模式探讨 [J]. 商业会计, 2015,(13):29-31。

[11] 郑璐, 张妍, 郭春萍. 中国中小企业网贷融资创新发展研究 [J]. 福建金融, 2015,(06):50-55。

[12] 宁曙然. 基于中小企业融资视角下的P2P网络借贷问题研究 [J]. 湖北经济学院学报（人文社会科学版) , 2015,12(09):44-46+51。

[13] 陈沛芝. P2P网贷兴起背景下中小企业融资问题研究 [J]. 现 代营销(下旬刊), 2015,(08):2-3。

[14] 赵素芳, 李毓. P2P网络借贷支持科技型中小企业融资探究 ——河南省为例 [J]. 河南商业高等专科学校学报, 2015,28(04):14-17。

[15] 刘晓从. 基于 P2P网贷的中小企业融资问题研究 [J]. 时代金 融, 2014,(02):216-217。

[16] 赵雅敬. P2P网络借贷缓解科技型中小企业融资难问题研究 [J]. 经济研究参考, 2014,(25):57-64。

[17] 孔令君. P2P网贷平台的中国难题与应对底线 [J]. 海南金融, 2014,(07):47-52。

[18] 张绍合, 柯可. 基于 $\mathrm{P} 2 \mathrm{P}$ 网贷平台的仓单质押融资模式设计 与创新 $[J]$. 金融理论与实践, 2017,(03):102-107。

[19] 王倩,施喜容. 论中小企业发展现状与融资困境 [J]. 对外经 贸, 2017,(06):105-107+137。

[20] 刘沙沙. 浅析P2P网贷平台下中国中小企业融资现状[J]. 西 部皮革，2017,39(12):94。 